\title{
Treatment with Aldose Reductase Inhibitor or with Myo-inositol Arrests Deterioration of the Electroretinogram of Diabetic Rats
}

\author{
Leslie C. MacGregor and Franz M. Matschinsky \\ Diabetes Research Center, and Departments of Physiology and of Biochemistry and Biophysics, \\ University of Pennsylvania School of Medicine, Philadelphia, Pennsylvania 19104
}

\begin{abstract}
Biochemical abnormalities in the retinal pigment epithelium of experimentally diabetic animals include increased sorbitol and decreased myo-inositol. Diabetes also causes a progressive reduction in the amplitude of the c-wave of the electroretinogram of the pigmented rat. The c-wave is generated by the retinal pigmented epithelium. Myo-inositol administration or treatment with sorbinil, an inhibitor of aldose reductase, arrested the decline in the c-wave. Therefore, hyperglycemia-associated defects in myo-inositol or sorbitol metabolism may be involved in the pathogenesis of the electrophysiological deficit of the diabetic retina. The homogeneous cell layer of the pigment epithelium may be a useful tissue model for studying the pathogenesis of the complications of diabetes.
\end{abstract}

\section{Introduction}

Vascular lesions of the retina are the major cause of blindness associated with diabetes of long duration (1). However, morphological, biochemical, and functional changes develop in the retina within several weeks of experimental induction of diabetes, long before vascular alterations are apparent. Pathological changes have been documented in the retinal pigmented epithelium (RPE) ${ }^{1}$, the cell layer that constitutes the outer blood retinal barrier. In experimental diabetes of a few weeks duration, the basal membrane of the RPE cells doubles in surface area and infolding (2), and increased dye permeability is observed $(3,4)$. The glucose concentration in the RPE is equal to serum level in normal and in diabetic animals (5). The RPE and all retinal layers in early diabetes show increased sorbitol and decreased myo-inositol (5). Electrophysiological impairment is evident in the progressive decrease in the amplitude of the c-wave of the electroretinogram (ERG) of the acutely diabetic rat (6). The normal c-wave of the ERG is associated with hyperpolarization of the apical membranes of the RPE cells, which occurs passively in response to decreased

Address correspondence to Dr. Matschinsky.

Received for publication 29 April 1985.

1. Abbreviations used in this paper: ERG, electroretinogram; RPE, retinal pigmented epithelium.

J. Clin. Invest.

(c) The American Society for Clinical Investigation, Inc.

0021-9738/85/08/0887/03 $\$ 1.00$

Volume 76, August 1985, 887-889 potassium in the outer retinal extracellular space after lightinduced hyperpolarization of photoreceptor cells (7).

Electrophysiological deficits are documented in nerve as well as in retina of early diabetic animals, and may share a common pathogenesis. Elevated serum glucose also causes reduced myo-inositol and increased sorbitol in peripheral nerves of diabetic animals (8-13). These defects are associated with reduced nerve conduction velocity (10-12). Nerve conduction velocity in diabetic animals can be normalized either by restoring normal nerve myo-inositol content by oral supplementation (10-12), or by preventing sorbitol and fructose accumulation by treatment with sorbinil $(11,12)$, an inhibitor of aldose reductase. Sorbinil treatment also restores normal nerve myo-inositol levels (11-13), implicating sorbitol and fructose accumulation in the fall of nerve myo-inositol, which may be central to the development of electrophysiological deficits in early experimental diabetes.

Correction of the hyperglycemia-associated sorbitol accumulation or myo-inositol decrease in nerve prevents the development of neural electrophysiological deficits in diabetic rats (10-12). Therefore, the present study was initiated to determine whether myo-inositol supplementation or sorbinil treatment alters the progressive decrease in the c-wave amplitude of the ERG of acutely diabetic rats.

\section{Methods}

Male pigmented Long-Evans rats that weighed $230-280 \mathrm{~g}$ at the beginning of the study were fed rat chow (Ralston Purina Co., St. Louis, MO) ad lib. The myo-inositol content of the rat chow, kindly analyzed by Dr. D. A. Greene with a previously described method (10), was $20 \mathrm{mg}$ per $100 \mathrm{~g}$ chow. ERG recordings were taken on all rats, which were then randomly assigned to normal or diabetic groups in each treatment category. After a 16-h fast on the evening of the first ERG, diabetes was induced by intraperitoneal injection of streptozotocin $(70 \mathrm{mg} / \mathrm{kg}$ in $1.5 \mathrm{ml} 0.9 \%$ saline, pH 4.5 ; Sigma Chemical Co., St. Louis, MO). Diabetes was confirmed by fasting serum glucose levels over $15 \mathrm{mM}$ both $3 \mathrm{~d}$ and $6 \mathrm{wk}$ after induction. Serum glucose was measured with a glucose analyzer (II; Beckman Instruments, Inc., Fullerton, CA) and serum myo-inositol was measured enzymatically (14). Treatments were begun the evening of streptozotocin injection, and consisted of a total daily dose of either $650 \mathrm{mg} / \mathrm{kg} m y o$-inositol or $10 \mathrm{mg} / \mathrm{kg}$ sorbinil divided into two equal doses and administered by gavage every $12 \mathrm{~h}$. At these doses, myo-inositol prevents peripheral nerve abnormalities (11) and sorbinil is present and active within the eye (15). Sorbinil, kindly supplied by Pfizer Chemicals Div. (Groton, CT), was solubilized as previously described (13). Direct ophthalmological examination of the eyes of each rat after the last ERG revealed no abnormalities.

For ERG recordings, the rats were weighed, then dark-adapted for $24 \mathrm{~h}$. Each rat was anesthetised with ketamine $(87 \mathrm{mg} / \mathrm{kg}$; Parke, Davis 
\& Co., Detroit, MI) and xylazine $(20 \mathrm{mg} / \mathrm{kg}$; Bay Vet, Div. Cutter Laboratories, Inc., Shawnee, KS), both intramuscular. The ERG responses were recorded with a bipolar contact lens electrode (BurienAllen; from Hansen Ophthalmic Development Laboratory, Iowa City, IA) and an ear clamp reference electrode. The lens electrode was inserted, and the pupil was dilated with $1 \%$ tropicamide (Alcon Labs., Inc., Fort Worth, TX). The rat was positioned so that its head and shoulders extended into a full-field (ganzfeld) diffusing sphere, with recessed light source that produced illumination of 3.0 footlamberts within the sphere. After $30 \mathrm{~min}$, a 10-s light stimulus was applied. Direct current potentials were recorded on a flat bed plotter and storage oscilloscope after preamplification of 1,000 -fold. A variable potential of $\pm 500 \mathrm{mV}$ was introduced between the lens electrode and the preamplifier to eliminate direct current potential offset caused by the interaction of various metal components of the electrode. ERG bwave and c-wave amplitudes were measured in microvolts at the points of maximum deflection from the isoelectric line during the first $6 \mathrm{~s}$ of the 10-s stimulus.

The statistical significance of measured differences between experimental groups was calculated using Student's $t$ test.

\section{Results}

Fasting serum glucose, measured in blood collected by heart puncture after the final ERG, averaged $8.4 \pm 0.2 \mathrm{mM}$ (mean $\pm \mathrm{SE}$, $n=23)$ in normal rats and $24.8 \pm 0.7 \mathrm{mM}(n=31)$ in diabetics. Final body weights averaged $413 \pm 5 \mathrm{~g}(n=23)$ for normals, and $254 \pm 6 \mathrm{~g}(n=31)$ for diabetics. Treatment with sorbinil or with myo-inositol had no effect $(P \geq 0.05)$ on serum glucose levels or body weights, shown by similar means and ranges in treated and untreated groups. Serum myo-inositol averaged $211 \pm 12 \mu \mathrm{M}(n=15)$ in myo-inositol supplemented animals and $45 \pm 2 \mu \mathrm{M}(n=38)$ in untreated and sorbinil treated rats. These averaged values include normal and diabetic rat sera, since diabetes caused no significant change in measured serum myo-inositol.

Representative ERG recordings are shown in Fig. 1. There was no significant difference in the b-wave amplitudes of the
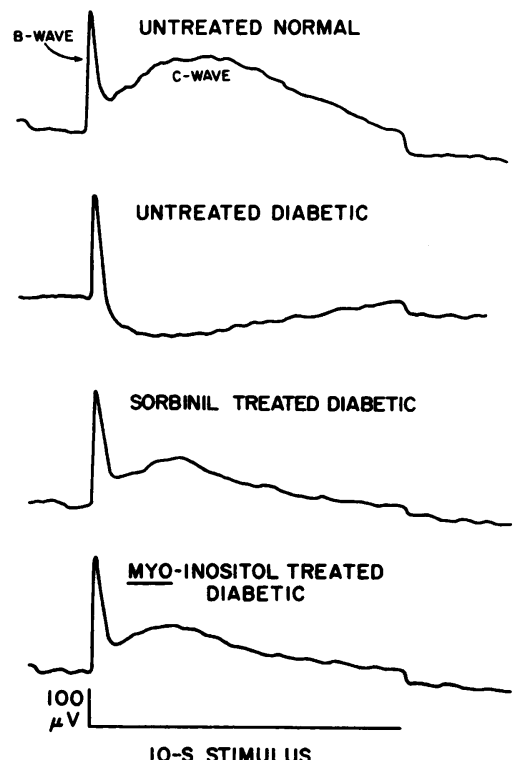

10-S STIMULUS

Figure 1. Representative ERGs of rats 6 wk after induction of diabetes. The ERG patterns of all nondiabetic rats were similar, regardless of treatment. different groups. After 2 wk of diabetes, the c-wave was significantly reduced $(P \leq 0.001)$ in all diabetics (Fig. 2). The c-wave amplitude continued to decrease in untreated diabetics, but was maintained by either myo-inositol or sorbinil treatment at the 2-wk level. With either treatment, peak c-waves of the diabetics were still significantly less than respective control groups, with the exception of the myo-inositol treatment group at $4 \mathrm{wk}$. The c-wave amplitude of diabetics treated with myo-inositol was significantly higher than the untreated diabetic response at both the 4-wk $(P \leq 0.01)$ and 6-wk $(P$ $\leq 0.00001)$ time points. The response of sorbinil-treated diabetics was significantly different than untreated diabetics $(P$ $\leq 0.00005$ ) after 6 wk of treatment, but not after 4 wk.

Mean c-wave amplitudes of normal untreated rats were significantly lower than in the initial ERG after 4 wk ( $P$ $\leq 0.01)$ and $6 \mathrm{wk}(P \leq 0.05)$. Although there was no significant change in c-wave response of myo-inositol-treated normal rats over the study period, the c-wave amplitudes of sorbinil-treated normals were less $(P \leq 0.002)$ than pretreatment recordings after $4 \mathrm{wk}$, but not after 6 wk.

The small (statistically nonsignificant) trend in our recordings over time was associated with polarization of the complex corneal electrode. To offset this factor, all ERG recordings for each of the four time points were collected within several days, with those of diabetic and nondiabetic animals recorded alternately. Therefore, the differences in c-wave peak between diabetic and nondiabetic rats appear to be valid.

\section{Discussion}

A trend toward decrease of peak c-wave amplitudes of the treated and untreated nondiabetic rats appeared to be present over the 6 wk of this study. Using similar animals and methods, but recording with a saline wick electrode, Pautler and Ennis (6) observed no change in peak c-wave values in nondiabetic rats over $19 \mathrm{wk}$.

The reduction of the c-wave of diabetic pigmented rats in this study, similar to previously reported measurements (6),

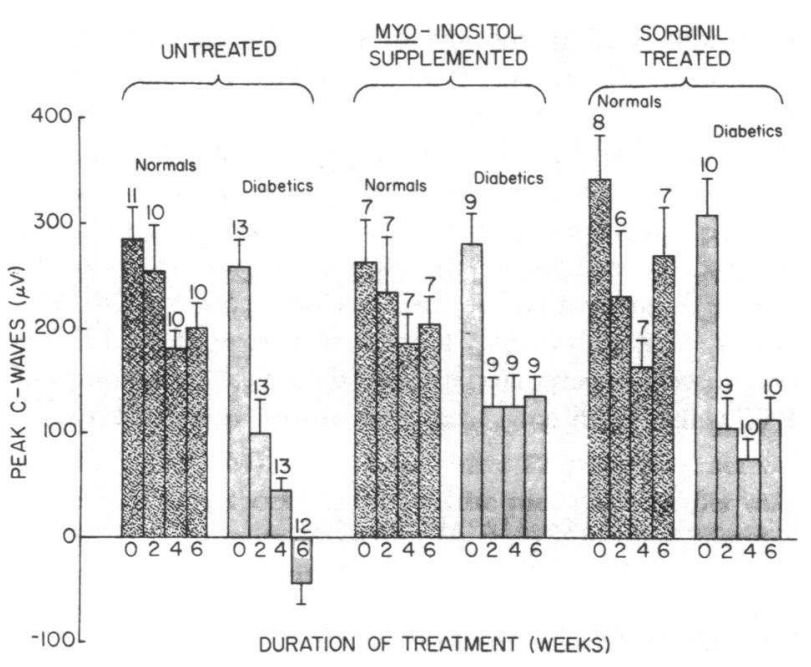

Figure 2. Peak c-wave amplitude (mean \pm SE) of ERGs of normal and of diabetic rats after different treatment durations. The number above each bar indicates the number of animals that were studied successfully at each time in the trial. See text for statistical treatment of the data. 
may reflect impaired ability of the apical cell membranes to hyperpolarize in response to reduced extracellular potassium. Decreased polarization responses might be associated with altered ion metabolism of the RPE, similar to that described in nerves of diabetics $(16,17)$. We have shown that either myo-inositol supplementation or sorbinil treatment also arrests the progressive reduction in the c-wave of the ERG of the diabetic pigmented rat. This is significant because an association is made between abnormal myo-inositol and sorbitol metabolism in diabetes and impaired electrophysiological response of a single cell layer. Note that in this context, alloxan diabetes causes a loss of $\mathrm{Na}^{+}-\mathrm{K}^{+}$-ATPase activity and an elevation of the sodium content of the RPE of the rabbit $(18,19)$. This result is similar to the known diabetic manifestations in peripheral nerve of diabetic animals $(16,17,20)$. Extrapolating from the results of sorbinil treatment or dietary myo-inositol supplementation on measured nerve $\mathrm{Na}^{+}-\mathrm{K}^{+}$-ATPase activity $(20,21)$, it can be postulated that treatments would also prevent the $\mathrm{Na}^{+}-\mathrm{K}^{+}$-ATPase loss and sodium accumulation in the RPE. This prediction is testable. It must be emphasized, however, that a biochemically plausible linkage between hyperglycemia, enhanced polyol pathway, myo-inositol depletion, lowering of $\mathrm{Na}^{+}-\mathrm{K}^{+}$-ATPase activity, sodium accumulation, and electrophysiological abnormalities cannot be made at this juncture.

The RPE, as the major component of the outer blood retinal barrier, is pivotal in determining the composition of the retinal extracellular fluid. Diabetes-related changes in this layer which altered the extracellular environment of the retinal capillaries might be involved in the pathogenesis of microvascular diabetic retinopathy. The cells of the retinal pigment epithelium may provide a unique model for studying the molecular basis of diabetic complications and their prevention or reversal.

\section{Acknowledgments}

The authors thank Mr. D. Montabana, Mr. K. Hansen, Mr. S. Summerfield, Dr. H. E. Kolder, Dr. A. M. Laties, and Dr. E. L. Pautler for their collaboration and advice, and Pfizer Central Research (Groton, CT) for the gift of sorbinil.

Dr. MacGregor is a fellow of the Veterinary Medical Training Program of the University of Pennsylvania, which is supported by U. S. Public Health Service grant GM-07170. This research was supported by National Institutes of Health grants AA03517, AM19525, AM21933, and NS14843; and by a grant from Pfizer Central Research.

\section{References}

1. Engerman, R., D. Finkelstein, G. Aguirre, K. R. Diddie, R. R. Fox, R. N. Frank, and S. D. Varma. 1982. Ocular complications. Diabetes. 31(Suppl. 1):82-88.

2. Grimes, P. A., and A. M. Laties. 1980 . Early morphological alteration of the pigment epithelium in streptozotocin-induced diabetes: increased surface area of the basal cell membrane. Exp. Eye Res. 30: 631-639.

3. Kirber, W. M., C. W. Nichols, P. A. Grimes, A. I. Winegrad, and A. M. Laties. 1980. A permeability defect of the retinal pigment epithelium. Occurrence in early streptozotocin diabetes. Arch. Ophthalmol. 98:725-728.

4. Tso, M. O. M., J. G. Cunha-Vaz, C. Y. Shih, and C. W. Jones. 1980. Clinicopathologic study of blood-retinal barrier in experimental diabetes mellitus. Arch. Ophthalmol. 98:2032-2040.

5. MacGregor, L. C., L. R. Rosecan, A. M. Laties, and F. M. Matschinsky. 1984. Microanalysis of total lipid, glucose, sorbitol, and myo-inositol in individual retinal layers of normal and alloxan diabetic rabbits. Diabetes. 33(Suppl. 1):89a.

6. Pautler, E. L., and S. R. Ennis. 1980. The effect of induced diabetes on the electroretinogram components of the pigmented rat. Invest. Ophthalmol. Visual Sci. 19:702-705.

7. Oakley, B., II, and D. G. Green. 1976. Correlation of lightinduced changes in retinal extracellular potassium concentration with c-wave of the electroretinogram. J. Neurophysiol. (Bethesda). 39:11171133.

8. Greene, D. A., and S. A. Lattimer. 1982. Sodium- and energydependent uptake of myo-inositol by rabbit peripheral nerve. Competitive inhibition by glucose and lack of an insulin effect. J. Clin. Invest. 70:1009-1018.

9. Gabbay, K. H. 1973. The sorbitol pathway and the complications of diabetes. New Engl. J. Med. 288:831-836.

10. Greene, D. A., P. V. deJesus, and A. I. Winegrad. 1975. Effects of insulin and dietary myo-inositol on impaired peripheral motor nerve conduction velocity in acute streptozotocin diabetes. J. Clin. Invest. 55:1326-1336.

11. Gillon, K. R. W., and J. N. Hawthorne. 1983. Sorbitol, inositol, and nerve conduction in diabetes. Life Sci. 32:1943-1947.

12. Mayer, J. H., and D. R. Tomlinson. 1983. Prevention of defects of axonal transport and nerve conduction velocity by oral administration of myo-inositol or an aldose reductase inhibitor in streptozotocindiabetic rats. Diabetologia. 25:433-438.

13. Finegold, D., S. A. Lattimer, S. Nolle, M. Bernstein, and D. A. Greene. 1983. Polyol pathway and myo-inositol metabolism: a suggested relationship in the pathogenesis of diabetic neuropathy. Diabetes. 32:988-992.

14. MacGregor, L. C., and F. M. Matschinsky. 1984. An enzymatic fluorimetric assay for myo-inositol. Anal. Biochem. 142:382-389.

15. Peterson, M. J., R. Sarges, C. E. Aldinger, and D. P. MacDonald. 1979. CP-45,634: a novel aldose reductase inhibitor that inhibits polyol pathway activity in diabetic and galactosemic rats. Metabolism. 28: 456-461.

16. Das, P. K., G. M. Bray, A. J. Aguayo, and M. Rasminsky. 1976. Diminished ouabain-sensitive, sodium-potassium ATPase activity in sciatic nerves of rats with streptozotocin-induced diabetes. Exp. Neurol. 53:285-288.

17. Brismar, T., and A. A. F. Sima. 1981. Changes in nodal function in nerve fibres of the spontaneously diabetic BB-Wistar rat: potential clamp analysis. Acta Physiol. Scand. 113:499-506.

18. MacGregor, L. C., and F. M. Matschinsky. 1985. Correlation of biochemical and electrophysiological abnormalities in retinas of experimentally induced diabetic animals. Diabetes. 34(Suppl. 1):13A.

19. MacGregor, L. C., and F. M. Matschinsky. 1985. Altered retinal metabolism in diabetes. II. Measurement of sodium-potassium ATPase and total sodium and potassium in individual retinal layers. J. Biol. Chem. In press.

20. Greene, D. A., and S. A. Lattimer. 1983. Impaired rat sciatic nerve sodium-potassium adenosine triphosphatase in acute streptozotocin diabetes and its correction by dietary myo-inositol supplementation. J. Clin. Invest. 72:1058-1063.

21. Greene, D. A., and S. A. Lattimer. 1984. Action of sorbinil in diabetic peripheral nerve: relationship of polyol (sorbitol) pathway inhibition to a myo-inositol-mediated defect in sodium-potassium ATPase activity. Diabetes. 33:712-716. 